\title{
Trends in the Contemporary Architecture of Amman
}

\author{
Dr. Saleem M. Dahabreh, PhD* \\ Department of Architecture, School of Engineering, University of Jordan, Queen Rania str. Amman, Jordan.
}

ORCID: 0000-0002-1659-2085

\begin{abstract}
This paper examines the architecture of Amman/Jordan. Immersed in tradition, but also open and cosmopolitan, modern Amman went through a series of political, cultural, and economic transformations, which resulted in developing an expansive and a multiple sense of identity. This is reflected in its architecture; largely diversified in scale and style ranging between modernity and tradition, from aesthetically pleasing to visually displeasing, and from culturally acceptable to totally alien. Through visual observation, this paper examines the architectural scene of Amman and attempts to give a preliminary classification of such diversified trends. The paper identified seven architectural trends ranging from the contemporary to the regional and neo-traditional. The afterthought of the paper concluded that these trends can be further grouped into three categories; formal contemporary, contextual, and eclectic, reflecting a more general attitude towards modernity, tradition, and development.
\end{abstract}

\section{INTRODUCTION}

Exploring issues of architectural identity and stylistic change in contemporary cities is problematic especially in an era of historical dis/continuity, rapidly changing socio-economic and cultural conditions, and technological advancements. The city of Amman is no exception; from its establishment as a small Circassian village in 1878 to a major metropolis of over four million inhabitants in the last decade, Amman's growth has been both dynamic and consequential (Pidler, 2011). As a city that is constantly changing, responding to social and spatial practices, state policies, and transnational influences, its urban and architectural identity are changing rapidly as well. Against this complex scene, this paper examines the architectural scene of Amman and attempts to identify its current architectural trends and classify them visually (fig 1).

Research in this paper is exploratory in nature; it addresses the visual appearance of the built environment of Amman in order to find distinguishable properties, which enable the grouping of its architecture into categories or trends. In architecture, researching similarities is within the domain of architectural style. Architectural style is a way of classifying architecture

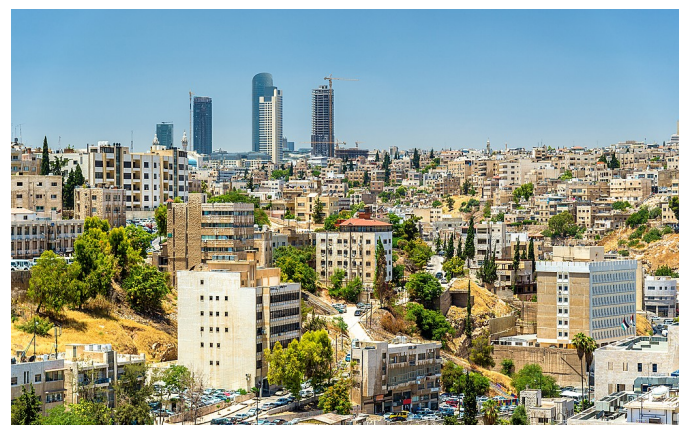

Figure 1: An over view of the city of Amman

according to characteristic features of design (Knight, 1994); buildings can be classified with reference to form, elements used, techniques and materials, time period, region, etc...Human observers are able to recognize, interpret and search for salient features in buildings or their representations in order to detect visual similarities (Jupp \& Gero, 2006). As such, visual observations and qualitative descriptions rather than morphological and typological analysis suffice the purposes of this paper. Despite its significance, this paper will neither discuss the internal lay out of the buildings and its reflection on the external facades, nor will it address in depth the socioeconomic conditions and cultural bases for the diversity of the architectural scene in Amman.

This paper focuses on the architecture of what is popularly known as" Western Amman", an area that has no exact geographic boundaries or legal qualification but agreed upon socially. The selection is not without merit; Western Amman is where "middle class" and "upper middle class" dwell, as such, it is an area where architecture can be freed from the constraints of pragmatic necessities and economic pressures giving architects the opportunity to experiment with designs that address new design ideas, aesthetics, technologies, and social and political orders. This allows architecture to visually express social, cultural, and aesthetic aspects freely, thus, acting as a visual metaphor that mirrors underlying value systems.

* Corresponding author 
Literature addressing the urban design and architecture of Amman is diverse, nevertheless, this paper is not an exhaustive review of all literature; rather a sample of that literature is reviewed: Al-Rifae (1987) published a book recording houses of Amman built in the 1920s and 1930s of the last century; Al Faqih (1993) addressed the formation of an architectural identity in Amman's houses; Mahadin (1994) talked about the attempts of many Jordanian architects to formulate an architetcural identity for Amman; Fethi and Mahadin (1994) addressed the spectrum of villa architecture in Amman; AlAsad et. Al. (1999) published a book talking about the old houses of Amman between 1920-1950; Rababe'h (2010) draws attention to the crucial problem of how to approach to design issues based on cultural identity within a global world; Daher between 2007 and 2008 published a series of articles addressing the effect of capital and neoliberalism on identity, architecture, and heritage of Amman. Pidler (2011) showed how the features of the city's history and development have shaped its unique identity. Jarrar (2013) investigated the work of four prominent architects in Amman to identify the cultural influences on its architecture post 1990s; Rjoub (2016) studied the emergence and development of Jordanian architecture and its relation to the architectural heritage of Jordan; Melnik (2019) talked about the urban identity of Amman. Nevertheless, there are no recent attempts to explore the complexity of the architectural scene. This paper presents such an attempt.

This paper will investigate what seems to be a chaotic architectural scene in order to identify and categorize architectural trends in the architecture of Amman. Since this paper is exploratory in nature, its primary aim is to set some background knowledge, describe and develeope an understanding about the architecture of Amman, and provide a platform for a more structured discourse about it. By no means its findings are conclusive or final; rather they are a preliminary attempt intended for future investigation. Nevertheless, classification presented within this paper is essential for structuring knowledge about architectural trends, for providing a sense of order within what appears to be a messy mixture, and for forming a necessary pre-condition for future in-depth analytic and morphological studies.

\section{Tracing Amman}

It is not within the scope of this paper to give an indepth review of Ammans' development; rather, a quick review of its development is presented to provide a background against which trends presented can be understood. Amman has three major characteristics that sets it apart from its fellow middle eastern capitals: firstly, while considered relatively new, the site on which the city is built has a long historic legacy. Secondly, the diversity of the city's population which was and is still formed by numerous waves of displacement and refugee movements, and this more than any other dynamic feature, shaped the city's identity. Thirdly, the lack of urban and social cohesion largely due to the failure of planning attempts because of continuous and rapid expansion (Pidler, 2011). These three charateristics had a major impact on Amman's architecture.
As for its historic legacy, although Amman has been characterized by newness - does not have the historical depth of Damascus or Cairo (Pidler, 2011), human settling in the site of Amman dates back to Rabbath Ammon of the Ammonites (13th C. B.C.), Philadelphia of the Greco-Roman Decapolis (3rd C. B.C.), or Amman of the Ummayads (7th C. A.D.). During the Ottoman Period in the 18th and 19th centuries, there was only a limited number of locals. In 1878, the site was resettled as a village for the Circassian immigrants. With the construction of the Hijaz railway, Amman became a small town in 1903, and with the establishment of Emirate of Trasnjordan under the British Mandate, it became a capital city in 1921 (Melnik, 2019). Since then, Amman has been reconstructed as a modern capital with around 4.5 million inhabitants. Nevertheless, the discontinuity in its history and its newness as a capital have always had an impact on its architecture and identity.

The highly diverse demographic of locals, displaced, and migrants greatly adds to the city's uniqueness. By the turn of the century, especially after the construction of the Hijaz railway, merchants from surrounding Arabic regions came to Amman. With the establishment of the Transjordan Hashemite Emirate under the British Mandate in 1921, the newly formed capital drew in migrants from other towns in Jordan and Palestine (Dumper and Stanley, 2007). The demographic structure of Amman changed drastically between 1948 and 2003; following Arab-Israeli conflict and the occupation of Palestine in 1948 and the West Bank in 1967, influxes of Palestinian refugees expanded Amman's size and population rapidly. The 1990-1991 Gulf crisis brought back around 300,000 Palestinian and Jordanian "returnees". The 2003 Gulf War brought about a great wave of migration to Amman in the form of some 200,000 Iraqis. With the Syrian conflict, Amman recevied more than 70,000 refugees. Amman transformed from a temporary destination for most of the migrants, to become a relatively lasting one. The diversity of the population ethnically, socially, culturally, and economically renders the establishment of a collective identity or the creation a sense of place a very difficult task. Furthermore, while these migrations might have had their economic benefits, they have put a great strain on the city's resources especially in terms of housing and infrastructure, which leads to the third characteristic, the spatial and physical disjunction of Amman along with the lack of social cohesion.

As new immigrants moved in, older inhabitants moved to new neighborhoods to the west, creating a pattern of expansion and movement of wealth in Amman from east to west (Pidler, 2011). As the population expanded, the urban fabric frayed apart away from the Downtown of Amman and spread uncontrollably in all directions. The hilly topography reinforced the disconnectedness of the growing city. As wealth ensued in the 1970s and 1980s, the desire amongst the financially capable for larger dwellings continued to push the city westward into agricultural lands, while eastern Amman was being populated with the less capable. The resultant urban sprawl and discontinuity of the city belied the numerous planning efforts made by the state to turn Amman into a contemporary, well planned, and structured city. 
International Journal of Engineering Research and Technology. ISSN 0974-3154, Volume 13, Number 7 (2020), pp. 1658-1670

(C) International Research Publication House. https://dx.doi.org/10.37624/IJERT/13.7.2020.1658-1670

In her PhD thesis, Jarrar (2013) drew a general idea about the architectural scene in Amman between 1920s and the 1990s. Following is a summary of that review; up until the 1940s, Amman had three dominant housing typologies; the Rewaq (arcade) house, Al-Finaâa (courtyard) house, and the Central Hall house which was a European influence adopted in Lebanon and spread afterwards further in Syria and Jordan (fig 2). With the introduction of new building functions e.g. governmental buildings, schools, and buildings for entertainment, a modernistic style started to encroach the territories of Amman (Daher, 2008 a).

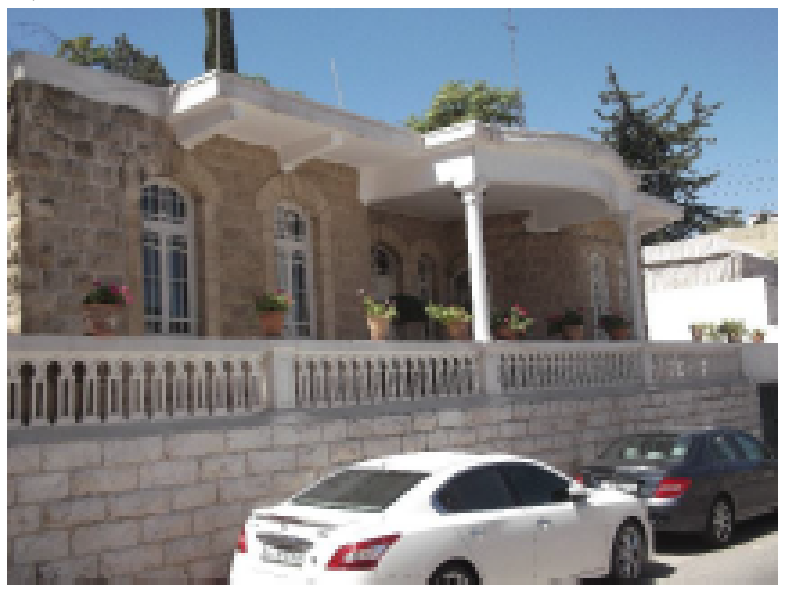

The return of many professionally educated architects from Europe, Lebanon, and Egypt, coupled with the complexity of an emerging city and radical change in life style due to changing socio economic conditions, created a new era of modernist influence began in Amman. By the 1960s', the international style was introduced especially in the architecture of hotels, public facilities, and university buildings (fig 3).

Figure 2: Old houses of Amman
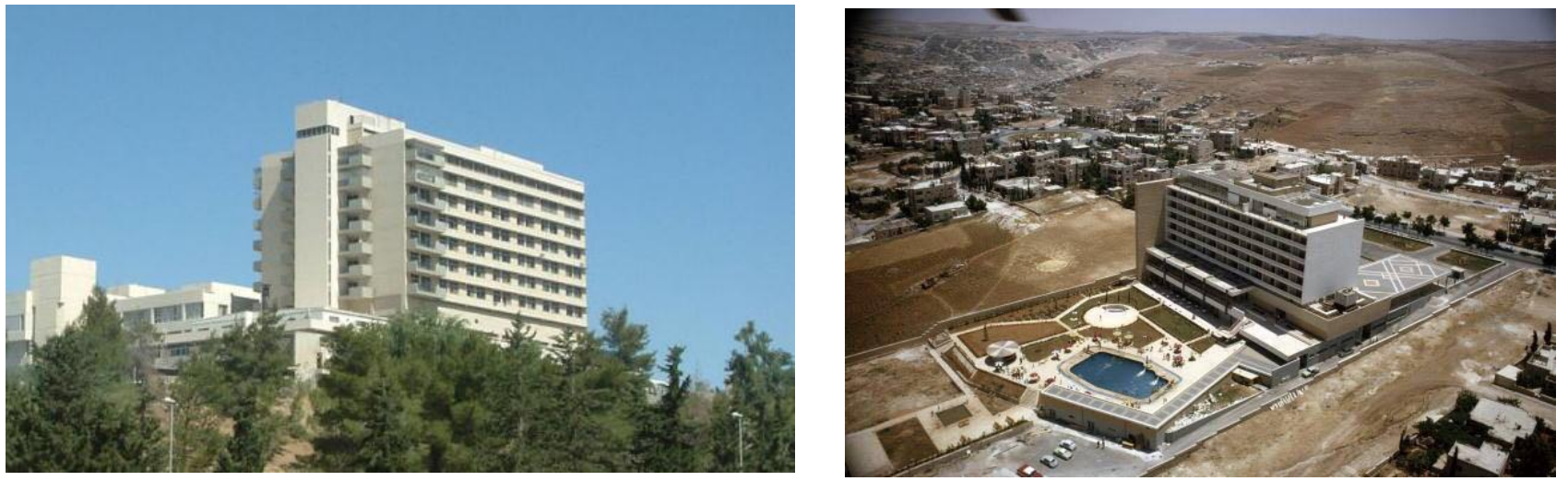

Figure 3 University of Jordan Hospital (left) and the Intercontinental Amman (right)

The period of the late 1960s up until the middle 1970s witnessed a domestic modern architecture that had both character and style; the modernist influence merged with local building tradition of masonry and stone to produce what can be labelled "domesticated modernity" (Daher, 2008 a) (fig 4). The period of the 1970s' up till mid 1980s' witnessed an economic boom due to rising oil prices, which influenced most sectors of society including the construction industry. Countries of the Middle East including Jordan initiated a new phase of development and construction led by both international and local architects. In Amman, two architectural trends dominated; an eclectic extravaganza of designs that exhibits wealth and financial power (fig 5), and a kind of picturesque Islamic revivalism that expressed nostalgia to the past (fig 6). These trends reflected a state of confusion in a culture that is both dogmatic and undefinable i.e. neither traditional in the authentic sense, nor contemporary in the modern sense; a mutated hybrid. By the mid of 1980s a new generation of practitioners came into the scene; architects who were interested in rediscovering and reinterpreting local Jordanian cultural values and expressing them architecturally. A sort of regional architecture was born and was gaining momentum among practitioners and university educators. Interest in the vernacular emerged and several public and touristic projects followed that trend. 
International Journal of Engineering Research and Technology. ISSN 0974-3154, Volume 13, Number 7 (2020), pp. 1658-1670

(C) International Research Publication House. https://dx.doi.org/10.37624/IJERT/13.7.2020.1658-1670
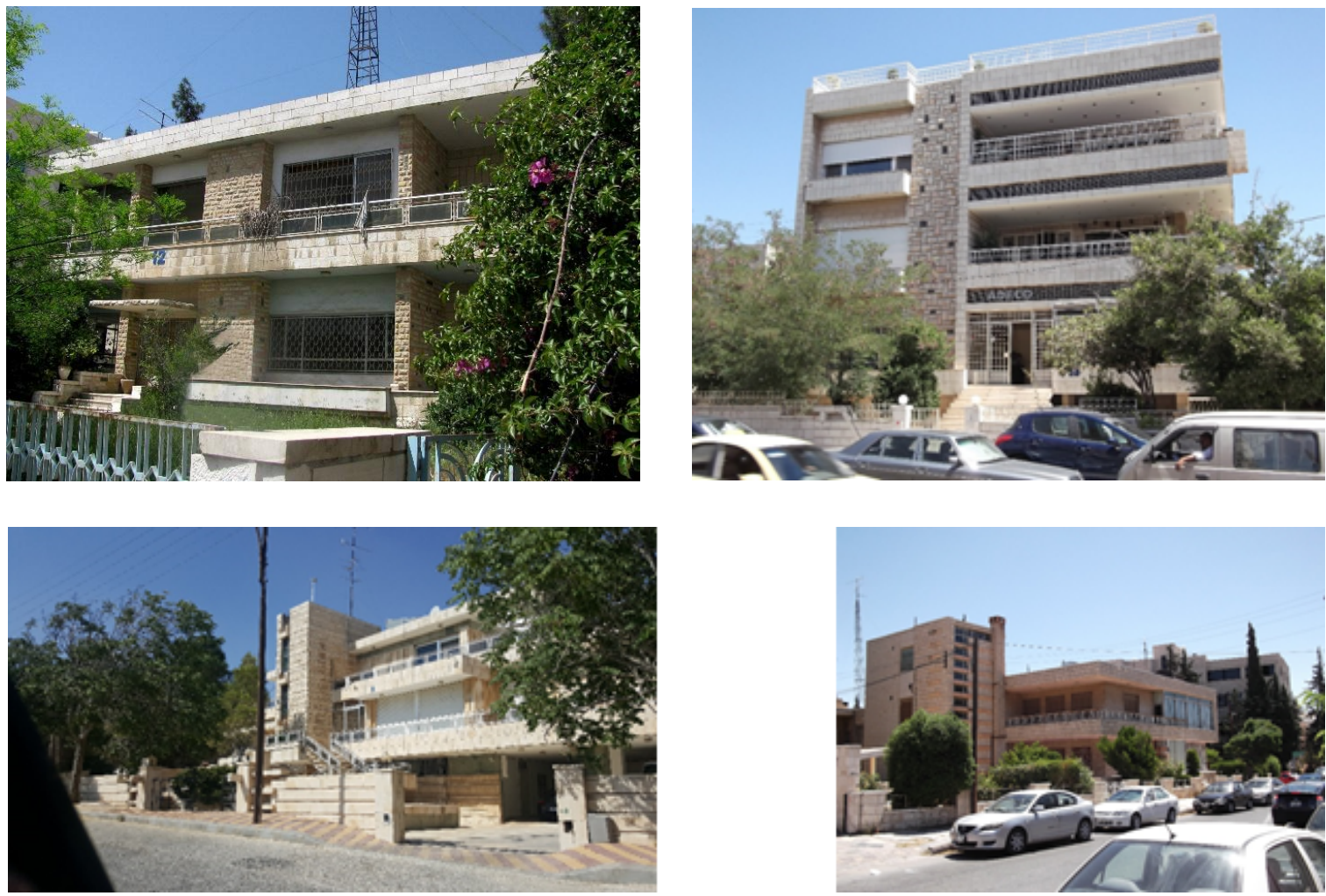

Figure 4: Modern architecture of the sixties and early seventies
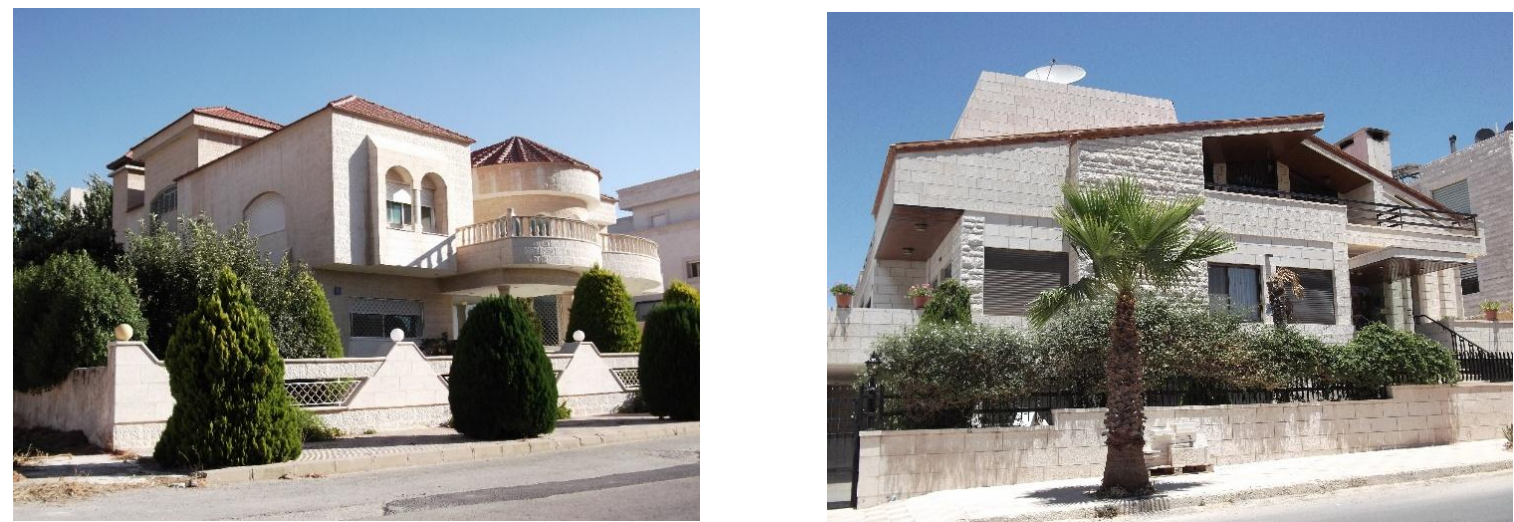

Figure 5: Eclectic architecture of the eighties

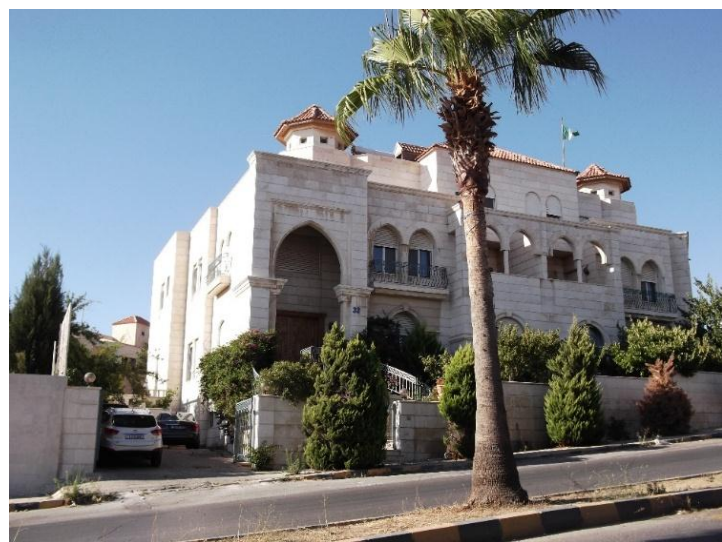

Figure 6: Islamic picturesque 
International Journal of Engineering Research and Technology. ISSN 0974-3154, Volume 13, Number 7 (2020), pp. 1658-1670

(C) International Research Publication House. https://dx.doi.org/10.37624/IJERT/13.7.2020.1658-1670

Rapid social and cultural change marked the end of the 1990s till mid 2000s due to globalization and rapid geo-political transformations. Globalization was supported by the rise of international neoliberal values and facilitated by the wide spread of digital media. Digital media, the free mobility of capital and goods facilitated the spread of a culture of consumption and advocated an optimum universal character of contemporary living (Ricoeur, 2007). This contemporary image stretched on all scales of human artifacts and commodities from small-scale products up to entire urban developments. The rapid geo-political transformations due to both the Gulf conflict and September 11th events affected Jordan directly; a new wave of immigrants from the Gulf, mainly Jordanian returnees and Iraqi refugees concentrated in Amman, brought their lifestyle, as well as capital (Jarrar, 2013). This influx of newcomers demanded large scale housing, which caused boost in residential building (fig 7) and the construction of high end residential villas.
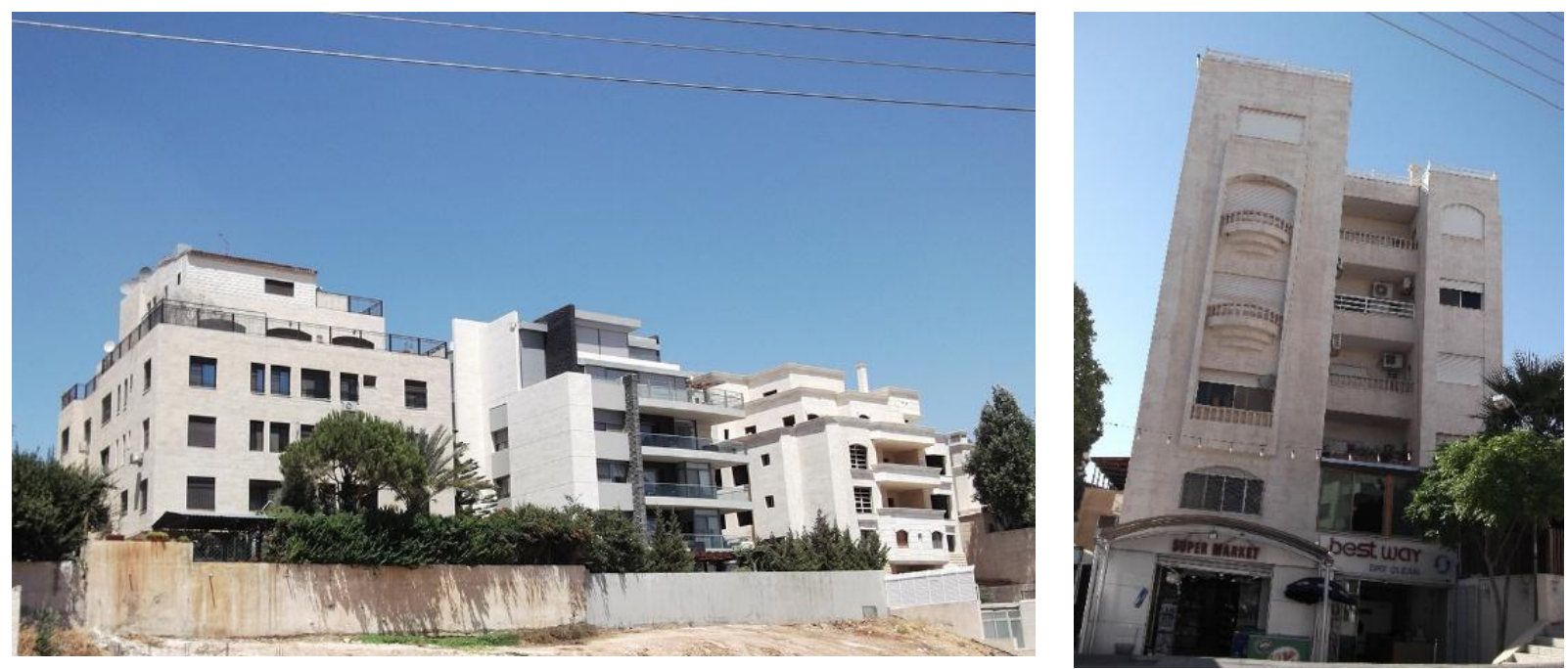

Figure 7: Residential buildings

The effect on the local architecture was immense; on one hand, Amman was forced into new urban developments of a contemporary image to compete in a world market and attract capital (fig 8). Its architecture was one of manufactured "sameness" with a universal mode of expression could be found anywhere and of an everywhere; thus buildings are reduced into a sort of tourist post card attractions or "free floating signs"(Al-Asad, 2008). On the other hand, a new "universal" architecture that expressed formal manipulation and an understanding of what contemporary theory of architecture started to emerge with practicing young architects (fig 9).

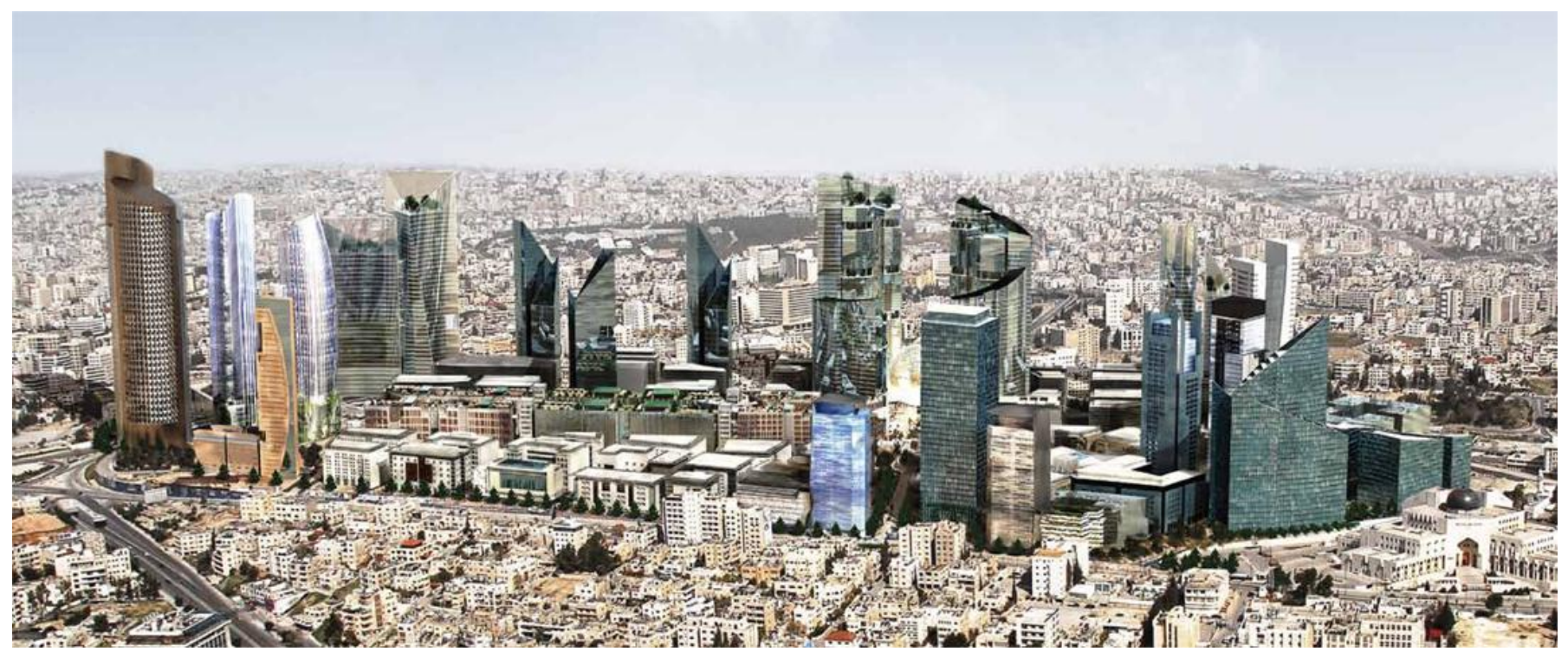

Figure 8: The Abdali development in Amman as an example of urban globalization 


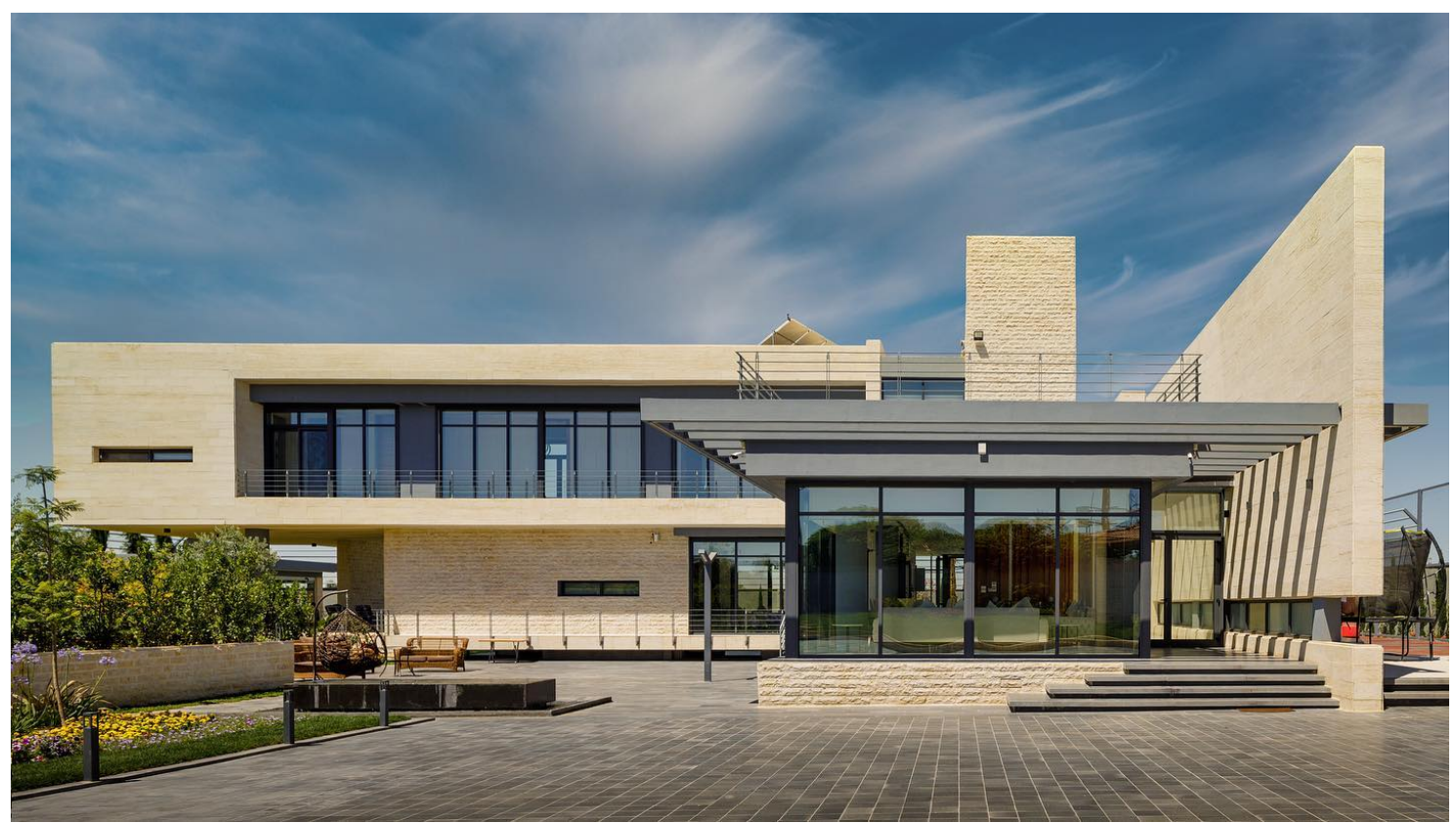

Figure 9: Private residence by Minimalist Architects

As can be seen from the review above, Jordan, in the last forty years, went through dramatic changes in its socio-economic conditions resulting in various shifts in its cultural environment. Accordingly, its architecture changed in response to the new cultural landscape; looking around Amman, a mixture of buildings ranging from small scale houses to high rise buildings of various functions and large housing projects following different architectural styles and schools of thought and varying between modern styles and traditional ones, from aesthetically pleasing to visually displeasing and from culturally acceptable to totally alien can be found. More recently, rapid urbanization, technological advances, and wide spread use of digital media, resulted in more diversification of Jordan's architectural built environment, depriving its architecture of its cultural and regional identity, and leading to a break in the continuity between its inherited morphology and the more recent architectural developments (Rababe'h, 2010). Such a condition, warrants close examination and preliminary classification of such changes.

\section{Style: a classification of the stylistic trends in Amman}

Concepts of style and stylistic change are central to the study of art and architecture; members associated within any discipline share a definition and classification of common concepts that constitute that discipline. The definition and classification of these concepts are necessary conditions to structuring knowledge in any discipline, communicating that knowledge, and giving insight into that particular discipline (Mitchell, 1990). Knight (1994) defined style as an ordering principle through which "artifacts" can be grouped together according to some distinguishable properties or features. As such, style can be described as consistencies among products of an individual, group, region, or time period that can identify them. For Schapiro (1953) these consistencies generally refer to physical form elements, formal relationships, and qualities (expression). Ackerman, (1962) regarded these consistencies as a kind of a language within which symbolic and formal conventions are organized into a coherent constructs similar to a grammar.

According to Knight, grouping of art products is a prerequisite to the study of stylistic change (knight, 1994). In architecture, the value of studying style is multifaceted: it can be a significant identifier of place and time; it is a system of forms with a quality and a meaningful expression through which values of the society are expressed and communicated; it forms a common ground against which innovations and the individuality of particular works maybe measured; and most importantly, it helps to account for the variations in styles and matching these variations with events and with the varying features of other fields of culture (Schapiro, 1953). Furthermore, theories of style and stylistic change not only provide a description of various styles but investigate the relation between them.

This study is exploratory in nature; it does not aim to explain why such styles appear, rather, it aims to identify visual similarities in buildings of Amman, which enables their grouping into architectural styles giving a sense of order within an otherwise apparently chaotic scene. Visual similarities in this research will address the overall form of the building as well as the design elements that are used. The detection of these visual similarities will be based on visual observations: according to Jupp \& Gero (2006), human observers are able to recognize, interpret and search for salient features in diagrams in order to detect visual similarities. This is supported by environment-behavior research where through observations, people recognize formal categories of defined architectural styles, state their stylistic preferences for a given building type, and identify the social meaning associated with housing of particular architectural styles (Groat \& Despres, 1991).

One issues that warrants attention here is the classification and 
labeling the different styles; the approach I shall take in this paper is based on the premise that architecture is analogous to language in terms its syntactic aspects especially with its structural and grammatical rules. As such, an architectural style can be regarded as a formal language characterized by a vocabulary and a grammar. The labelling of styles in this paper is based on the distinctive formal features of the vocabulary that typify that certain style, at the same time, adheres to the canonical definition as agreed upon by various authors.

Through the initial survey of buildings of Amman, the following styles were identified:

\section{International Architecture}

This trend refers to architectural designs that employ the vocabularies of the international style; simple rectilinear designs, the use of modern material, structural honesty, horizontal windows, pure forms, etc. This trend started in Jordan after its independence and even in the earlier phases as a part of the modernization process. Western Modernism was associated with development, hence the western model is to be followed; modern architecture to express a modern society (fig 3). This meant a search for technological solutions, functionality, and buildings as self-referential systems that express their functions and mode of construction (Kulb, 1992). The use of modern architecture was a readymade response to designing large scale projects such as universities, hospitals and large scale housing projects in which the traditional architectural was not able to cope with. it si also clear in the architetcure of banks and office buildings especially with boxy forms and extensive use of glass. Buildings conforming to this group are characterized by: the simplicity and clarity of forms with the elimination of

detailing and decoration, orthogonal designs with a visual emphasis on horizontal and vertical lines, materials honesty in expression and structure, the visual expression of structure, the extensive use of industrially-produced materials and the adaptation of machine aesthetic, and the illusion to the International Style of modernism (fig 10).
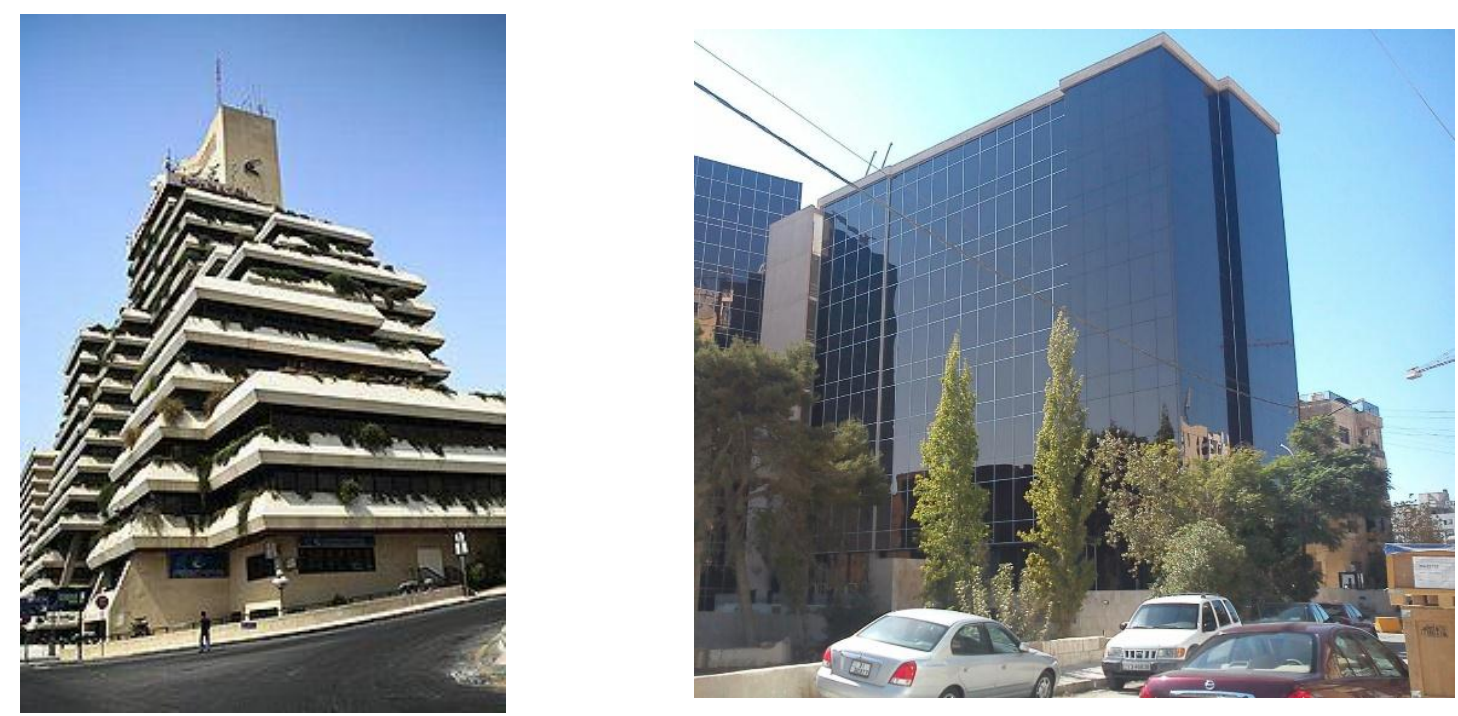

Figure 10: Samples of modern architecture

\section{Eclectic Architecture}

Eclecticism as an architectural style that started in the 19th and 20th-centuries. It refers to any work of architecture that incorporates either elements of traditional motifs and styles, decorative aesthetics and ornaments, structural features, and so on, or any design feature that originated from other cultures or architectural periods. Most of the architectural built environment in Amman belongs to this trend; a pitched roof combined with arches, strange shapes and onion like domes, the use of traditional vocabulary to express a modern plan, etc. The dominant players in this trend are the demands of the clients, the demands of the market, and architects' capabilities and desires. This trend is mostly followed by mass production designers and profit makers who were supporting commercial values as aspects affecting the quality of the produced architecture.

This trend still widely spread today, largely dominated the scene in the late seventies and the early eighties due to the increased wealth and the need to express this wealth by being different by the means of using different forms, expensive materials and following different styles. Nevertheless, some architects who work in this trend practice a kind of organized eclecticism, where they are aware of what they are doing and they do it according the codes of aesthetics and implying a certain rationality in their design solutions. It should be noted that this kind of architecture results from the freedom in the architectural expression and from the state of confusion of the society (fig 11). 

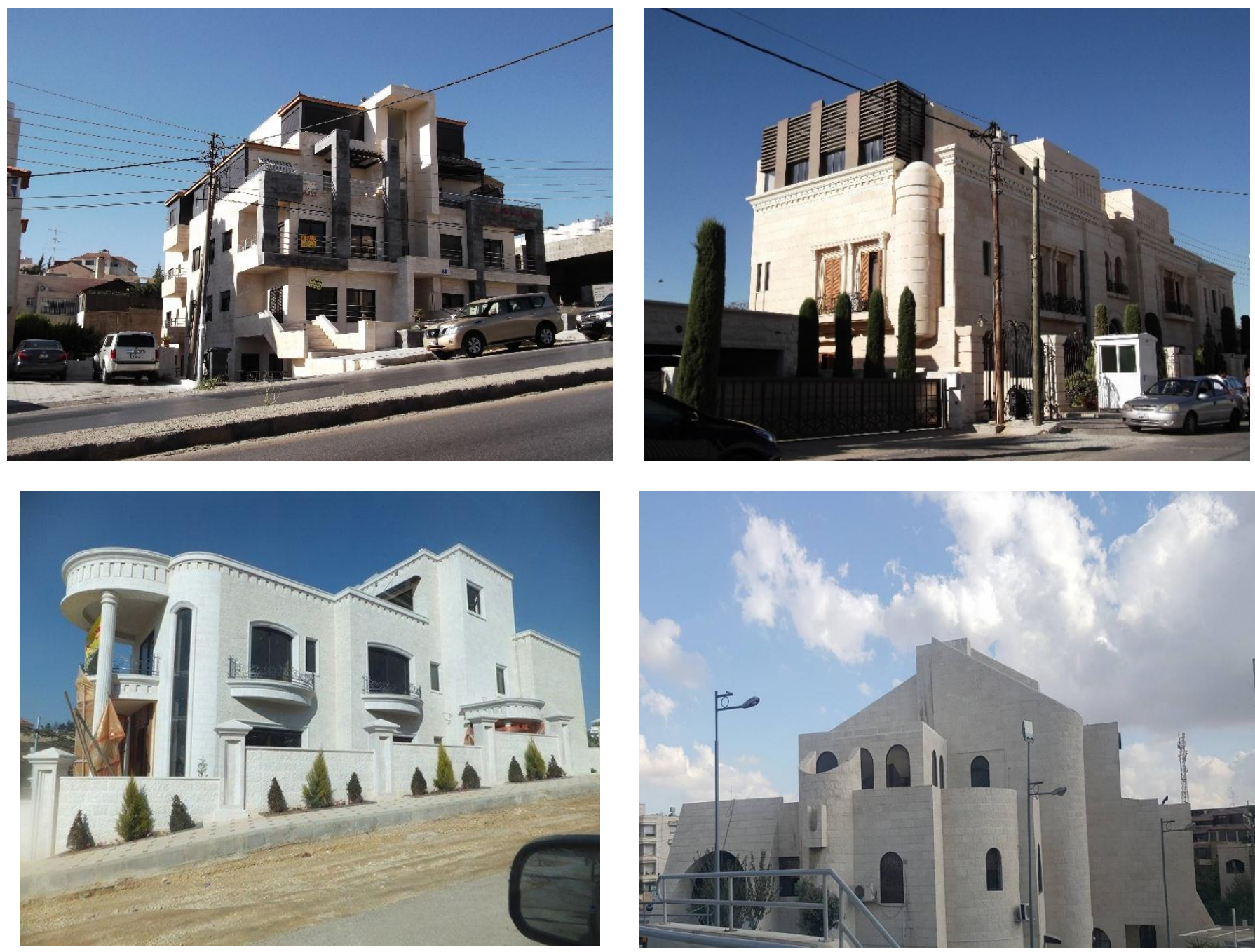

Figure 11: Eclectic architecture of Amman

As a result of the loss of the architectural identity and the visual chaos, some architects began to question the forms used started to search for an architectural identity through built forms; they began to look back at the rich repertoire of past architecture as an active source for their designs. This return was meant to establish the identity that was seemingly lost. This trial took the form of four trends, each one agrees on the use of tradition to give the identity but what source of reference to be used and the way to deal with that reference is different in each one of them.

\section{Neo-Vernacular Architecture}

Vernacular architecture, often refered to as 'architecture without architects', refers to buildings made by local craftsmen. In contrast to what is known as polite architecture, vernacular architecture is based on a tradition of building mostly related to social organization, availability of materials in the surrounding environment, and depending on unprofessionally trained builders. This type of building develops over time and experience within its own limits. It is charaterized by the use of available local building materials and simple utilitarian forms. In the context of Jordan, it is an attempt to revive the image of the village architecture found in the rural areas of Jordan with the use of the vernacular elements and treatments such as the use of local building like rough stones and mud, spontaneous massing and the manipulation of opened and closed spaces. Most attempts in neo-vernacular architecture fall under what Ozkan (2007) labelled interpretive vernacularism, an approach to bringing a new life to vernacular heritage for new and contemporary functions. The widest area of the application of this approach is the architecture for tourism and culture (fig 12). In that case, this trend did not exceed the renovation of some of the existing buildings either for private use or for renovating some villages utilizing modern technology to give a desired image for commercial purposes. It can be said that this trend did not exceed the theme of fashion for recreational purposes. 

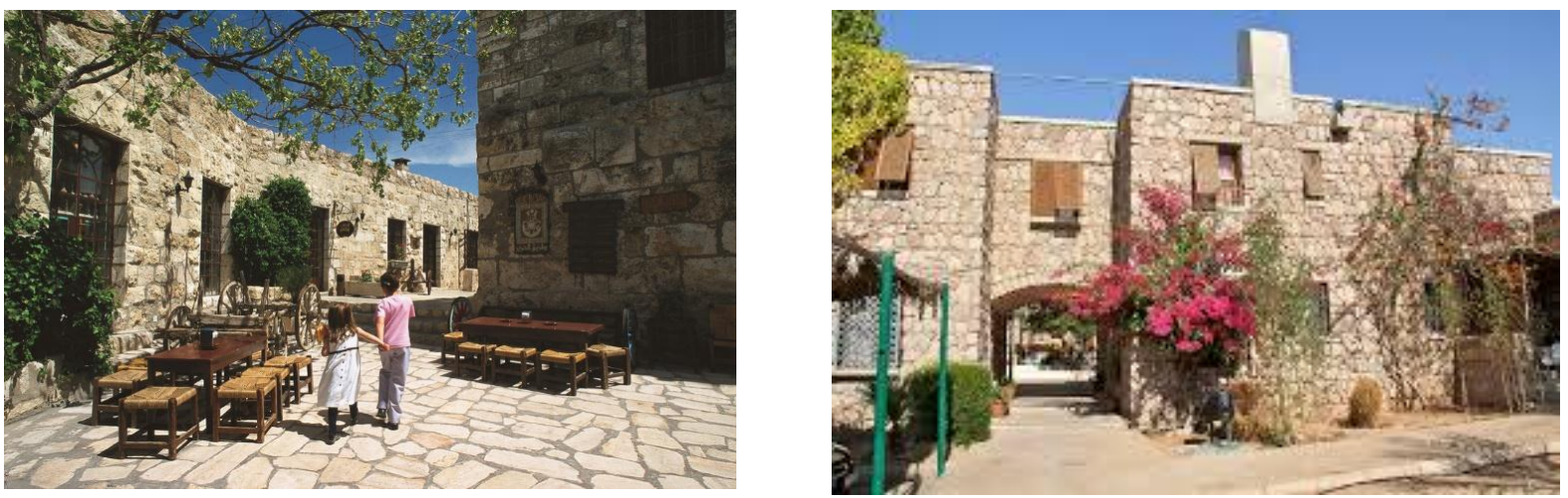

Figure 12: Kan Zaman Restaurant (left), and the SOS Village (right)

\section{Regionalized Modernism}

Regionalized Modernism is a term used "to characterize building design that opposed the standardizations of an" International Style" (Herring, 2009, p 2). According to Canizaro (2007, p 20), regional modernism "is a theory that supports resistance to various forms of hegemonic, universal, or otherwise standardizing structures that would diminish local differentiation". The theoretical base of this trend is based on the concept of "appropriate modernity" developed by Cristián Fernandez Cox in 1984 (cited in Schmitz, 2009). This concept assumes the presence of several parallel modernisms, not a singular one, each with its character and history. Here international modernity is used to uncover the real modern identity that coupled with unique responses to particular climates, places, and cultures. Thus, the corner stone of this approach is accepting modern architectural theories, aesthetical values and technology, and adopting it to the local context in which it is used.

Through the choice of the modern theories- based on the social values and the norms of the community- that are suitable for the local context and the modification of the regional architectural vocabulary to be well suited for modernity, architects give form to their buildings (fig 13). This concept of regionalized modernism is very close to but not exactly equal to what Ozkan (2007) called Abstract Modern Regionalism where modern architecture incorporates the abstract qualities of regional architecture such as massing, solids and void, proportions, sense of space, and use of light seeking to bring back to existence the cultural issues.
This trend based on the modern principles and holds the local tradition through the features it uses, manages to produce an architecture that is aesthetically pleasing and theoretically acceptable but still hasto be developed more so as to become a school of thought with principles rather than a trend carried by some architects.

\section{Experimental Regionalism}

"Regional architecture" as a term was first coined in 1981 by Alexander Tzonis and Liane Lefaivre, but it was Kenneth Frampton who gave it its most famous elaboration in his canonical essay on "Critical Regionalism" (1983). This trend finds its theoretical roots at the intersection of Ozkan's (2007) concrete modern regionalism, Curtis' (1986) authentic regionalism, and Frampton's (1983) critical regionalism. Concrete modern regionalism refers to the use of design of regional architectural elements and features in contemporary designs. Authentic regionalism refers to an architecture that finds unique responses to conditions of climate, place, and culture not necessarily by using design features but by reinterpreting and transforming values and principles of the past, thus referring to a way of thinking. Critical regionalism calls for the adaptation of tradition to meet the requirements of the contemporary times.
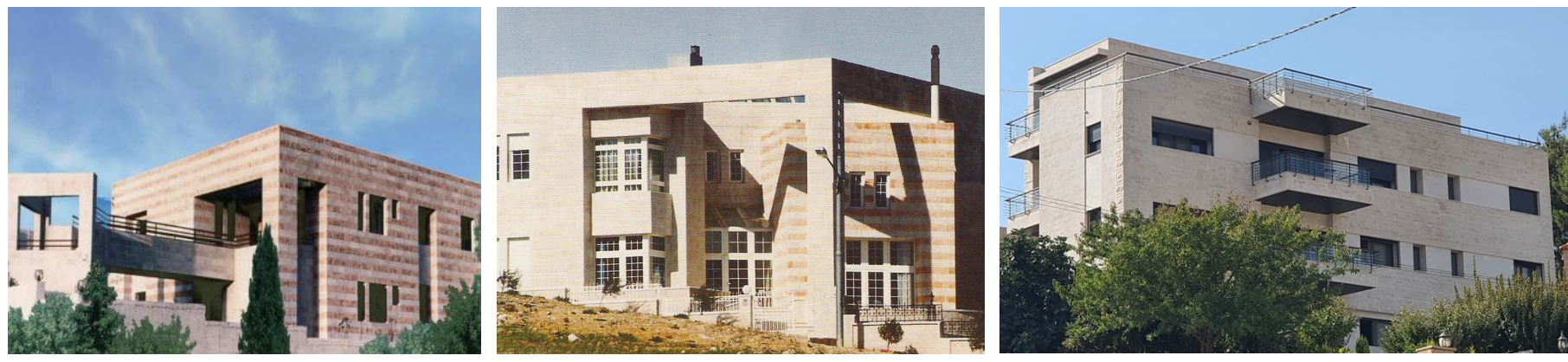

Figure 13: Modernity with a regional feel 
The basic point of reference for this trend is the local regional architecture with its aesthetics, treatments and architectural vocabulary. But since one dwells in the present, this architecture has to suit and reflect present time. So, architects experiment with the forms of the regional architecture such as the vaults, materials, typology of openings-double windows with segmental arches and punches-and other climatic and social treatments such as the courtyard in order to reach a form that is suitable for the contemporary life and still holds the strong image of the past, as if they are trying to give a new image of the past through the manipulation and transformation of its forms (fig 14).
One point to mention here as argued by Frampton (1983) is that regionalism differs from critical regionalism where while regionalism is about the context and customs of making buildings in a particular region with its own distinctive features, critical regionalism is an intellectual construct to counter the modernist and post modernist's lack of identity and disregard of context. At the same time, as regional architecture closely parallels vernacular architecture in its response to the locallity of context, it nevertheless incorporates modern building materials and technologies.
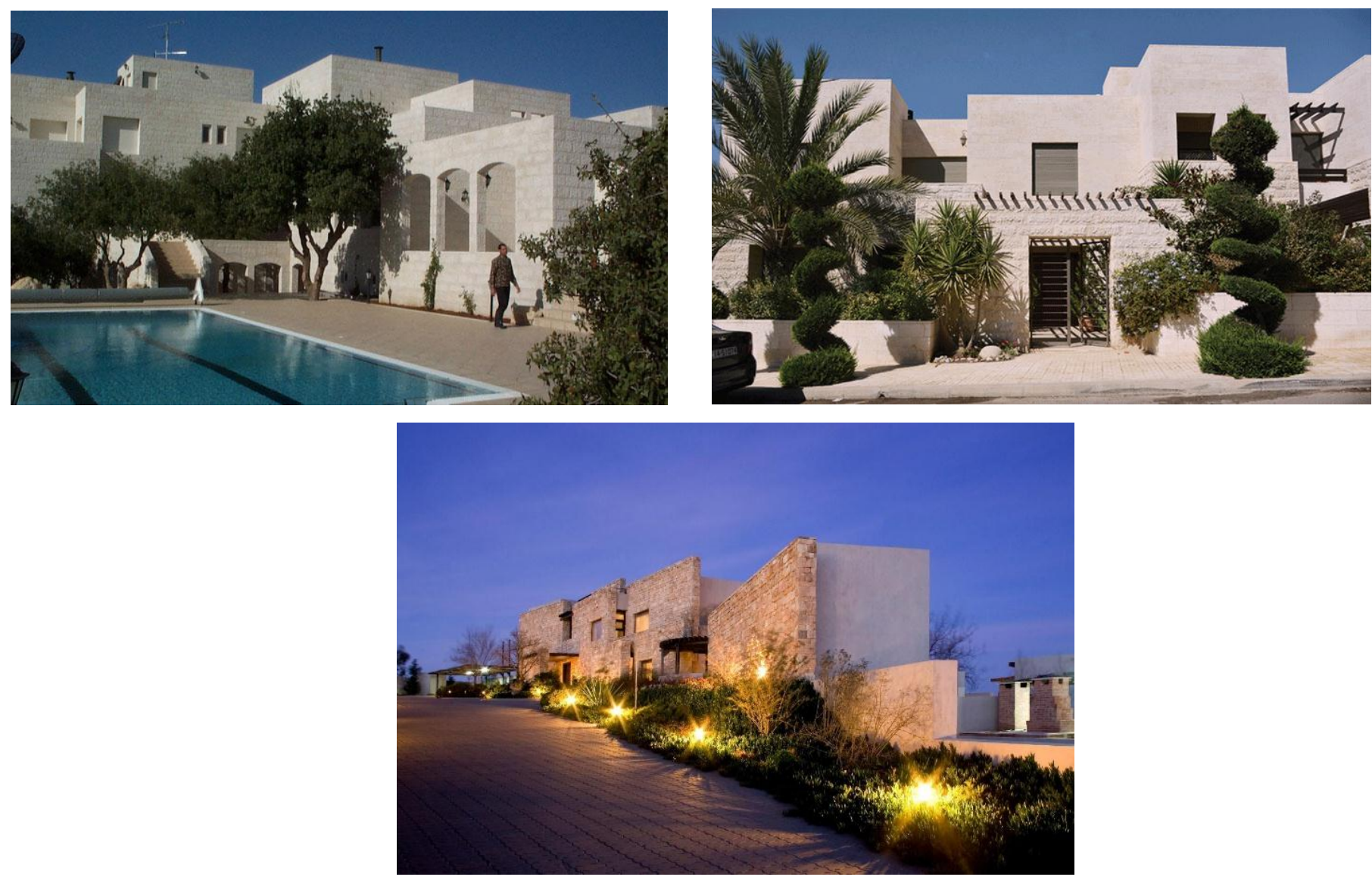

Figure 14: Projects exemplifying Experimental Regionalism

\section{Neo-Traditional Architecture}

Traditional architecture is a way of building that extensively uses the familiar symbolic forms, elements, and features of particular culture, of particular people and particular context. As such, traditional ${ }^{2}$ architecture is an architecture that takes into account past styles that were prevalent to a region or area. When one talks about Islamic architecture ${ }^{3}$, one refers to an architecture style that finds its highest expression in religious buildings such as mosques and Madrasah. This style is characterized by stylistic features and design features of design such as domes, arches, vaults, colored stone intentionally incorporated to reflect religious believes (fig 15).

\footnotetext{
${ }^{2}$ The term Traditional Architecture is generally used to refer to the architectural heritage in general including the regional architecture and the Islamic one but in the course of this research it would be used to refer to the Islamic architectural heritage without the regional one.

${ }^{3}$ The term Islamic architecture is greatly debated these days as it is a legacy of orientalism and in the current time the term Architecture in the Islamic Context is used, since spread over a vast geographical area over a period of more than 1400 year in which many local styles developed. For further discussion see Mohammad Alasad 'Views in the Concept of Islamic Architecture: Return to the Aspiration of Islamic Architecture is not mere copying but Development', in Alhayat, 14-5-1992, p19. (in Arabic)
} 

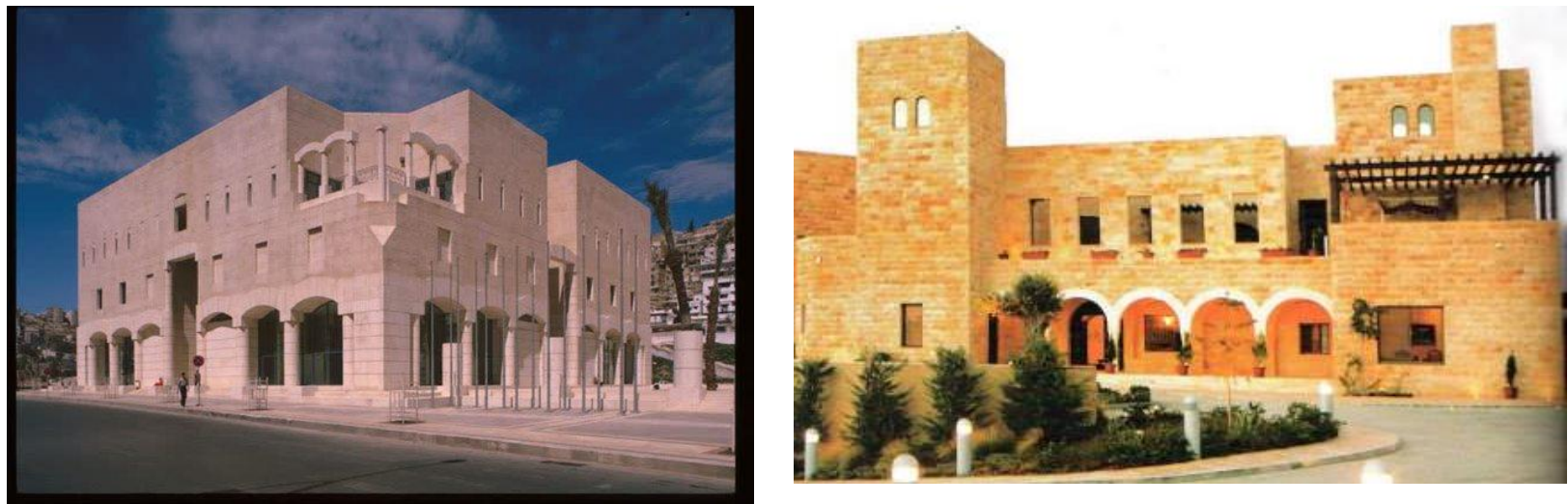

Figure 15: The municipality of Amman

Neo-traditional Islamic architecture is analogic to Ozkan's Concrete regionalism, which borrows regional expressions, elements, fragments, or entire buildings, in a certain region, except for the fact it only builds on heavily religious buildings that are considered symbolic of Islam. When new buildings are loaded with design features that have spiritual values or symbolic relevance, they become much more acceptable, owing to the values attached to the original source (Ozkan, 2007). This creates a sense of continuity and connection to the past, which helps to maintain a traditional look and feel.

Relying on traditional architecture takes two forms: picturesque employment that borrows and copies forms and features that are symbols of Islam due to their association with Islamic monuments. These features include domes and vaults, and different types of arches among others. Authentic traditionalism that employs general rules and principles that lie behind the established forms and types, which implies the rediscovery of the processes that lead behind the forms in order to be able to produce new typologies and this is rarely the case. ${ }^{4}$

\section{Contemporary Formal Architecture}

Generally speaking, contemporary architecture is defined as the architecture of the present day. It is based on the intention to

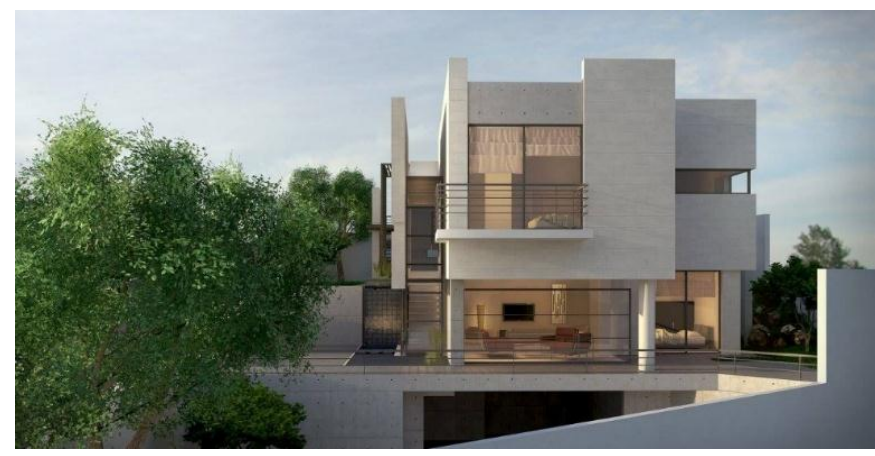

design and build things that are innovative and different from what was done in the past or what is usually done mundanely today; it offers a multitude of architectural choices, provided that they stand out from what is normally done. It breaks away from the processes and ways of thinking that have become standard. As it is not an architectural movement of a distinctive historical style, it has a high level of variety. However, this doesn't stop some common traits from being observable within contemporary architecture. The architecture of this trend aims to create compositions/ sculptures with a formal base.

'Contemporary' means simplicity in form and design; formally speaking, it is based on abstraction, which is created by clean lines, basic shapes, and forms. Thus, simple, plain, geometric forms, rectangular shapes, and linear elements make the characteristics of contemporary architecture. The overall form is either a pure platonic form in its generic state or an ensemble of basic design elements and volumes creating distinctive spaces in-between (fig 16). Another distinctive feature is the use of new materials or new use of materials like glass, wood, brick, and metals for both the interior and the exterior. Windows and openings are larger and more plentiful; besides the horizontal strips, multiple openings and their uncommon positioning, panoramic windows, window walls, and skylights have all entered the playing field.

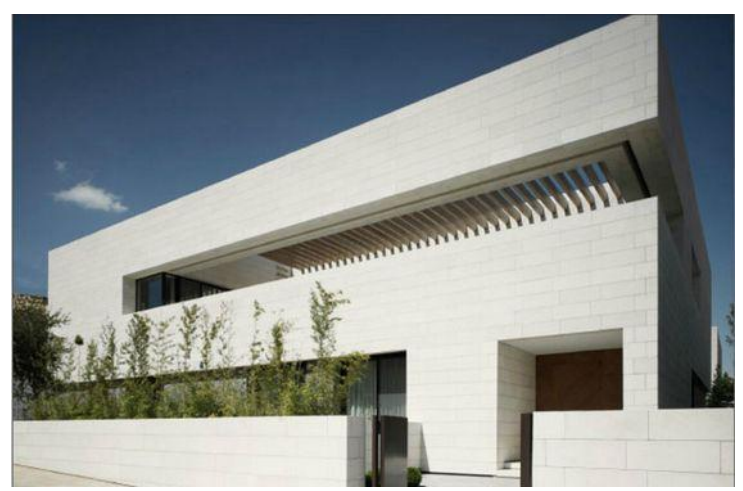

${ }^{4}$ The work of Henning Larsen in the Ministry of Foreign Affairs in Saudi Arabia is an example of extracting rules behind the traditional architecture. 

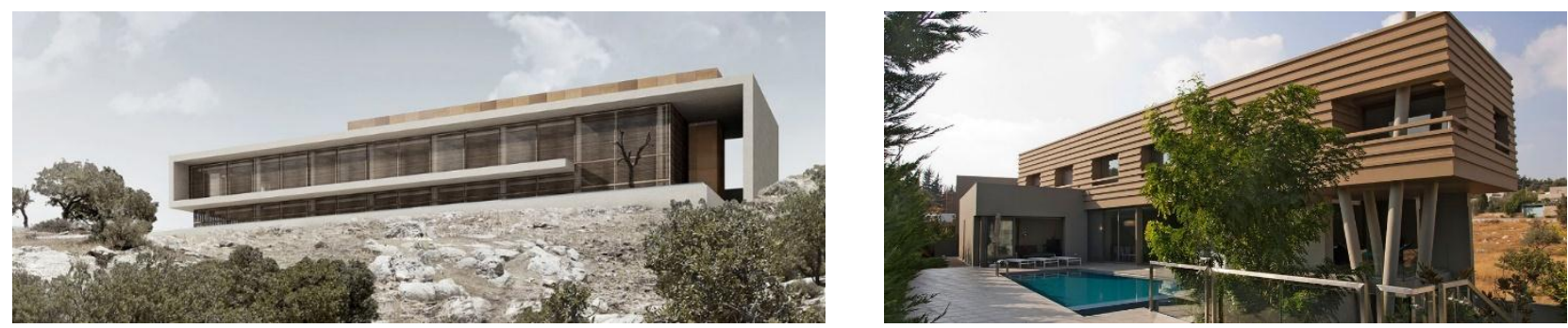

Figure 16: Samples of the contemporary architecture of Jordan

\section{After thought}

The aim of this paper was to explore the architectural scene of Amman. In a seemingly chaotic architectural scene, visual observations identified seven trends: international, contemporary formal, eclectic, neo-vernacular, regionalized modernism, experimental regionalism, and neo-traditional. Emergence of these style is attributed to rapid and complex socio-economic and cultural transformations, realities of the present day of globalization and power of digital media, issues of change and historical continuity, and most importantly, the search for an architectural identity.

These seven trends can be further regrouped into three main categories: contemporary formal, contextual, and eclectic. The contemporary formal is based on a notion of architecture as an autonomous system that is timeless and contextualess; architecture has its own laws, although subject to historical change, that come from inside the system. As such, its laws are universal and transcend the specifity of time and space. Accordingly, architecture is regarded as formation in which architectural form is displaced from its pragmatic surrounding conditions, giving priority to internal rules and mechanisms specific to architecture, without necessarily denying the presence of these conditions and responding to them. The contextual category responds to the specifity of the physical and socio-economic conditions of its context, which helps to distinguish architectural works, create a sense of continuity and connection to the past, and help an area maintain its local and regional identity and feel. Through the use of architectural features and elements, reuse of material, and overall formation, architectural works maintain a link to the past styles of building and stay consistent with an overall building design specific to that area. Thus, contrary to the former, Contextualism emphasizes figuration and locality rather than abstraction and globalism. Contextualism includes experimental regionalism, neo-vernacular, regionalized modernism, and neo-traditional. All of them, except for regionalized modernism, attempt to establish an architectural identity based on the past, an identity that reflects the culture of the region and defines an image for itself against another.

It should be noted that the difference between regionalized modernism and experimental regionalism is not a thin line; rather it is a margin within which many works of architecture are found. The difference can be noticed through asking the main question is whether one is trying to create a regional modern identity or a modern regional identity? The answer to this question lies in the starting point; if one is trying to adapt the modern to respond to the existing cultural norms then one is tackling regionalized modernism. This would mean the selection of what is appropriate of the modern according to the traditional norms and values and the rejection of what is not.
If one is adjusting the past to the modern times, then it is a modern regionalism. This implies the selection of the best of the traditional heritage in accordance with its suitability to the modern times. Nevertheless, the issue here would be how far into past one should go, criteria for selection, and the adjustment process.

The third trend, eclectic is being neither here nor there; it literally reflects the current state of social and cultural confusion. It is this trend that is expressive of the current conditions and mostly characterizes the pop intellectual scene. It represents the bare truth and its value lies in it being a warning sign that triggers study and action.

The presented categorization is linked to a wider discourse about modernity, tradition, and development. Issues arise because of the ambiguity of the three terms and their relationships. Nevertheless, if one is critically consciousness about them and able to engender a specific sense of self while attending to universal cultural elements as well as to the specifics of place, then a critical progressive attitude develops, which helps to establish a contemporary identity.

By no means has this paper claims these trends are exhaustive or clearly defined; rather, they require further investigation. These trends are meant to provoke questions of cultural identity in an age of globalization and an architectural identity in an age of theory and vast advancements in material, technology, and construction; questions of architectural documentation and analysis of this vast and rich repertoire; questions of how the issues of appropriate modernism, authentic regionalism, and critical regionalism be applied to the local context of Jordan. But most importantly it seeks answers to the seminal question of Paul Ricour (2007): "How to be modern and to continue the tradition, how to revive an old dormant civilization as part of universal civilization."

\section{REFERENCES}

[1] Akerman, J. S. (1962). A Theory of Style. The Journal of Aesthetics and Art Criticism. Vol. 20, No. 3. pp. 227-237. Wiley: on behalf of The American Society for Aesthetics. DOI: 10.2307/427321

[2] Al-Asad, M. (1999). Houses of Jordan. Routledge

[3] Al-Asad, M. (2008) The Contemporary Built Environment in the Arab Middle East. In Architecture and Urbanism in the Middle East: View Points Special Edition. Washington DC: Middle East Institute. pp. 26-28 
International Journal of Engineering Research and Technology. ISSN 0974-3154, Volume 13, Number 7 (2020), pp. 1658-1670

(C) International Research Publication House. https://dx.doi.org/10.37624/IJERT/13.7.2020.1658-1670

[4] Al-Faqih, S. (1993) House Formation and Architectural Identity in Urban Amman. Open House International. Vol. 18, no. 2, pp. 21-27

[5] Al-Rifae, T. (1987). The First Houses of Amman. Jordan: Jordan University Publications. (In Arabic).

[6] Abdelmajeed Rjoub, A. (2016). The Relationship between Heritage Resources and Contemporary Architecture of Jordan. Architecture Research 6(1): 112. DOI: $10.5923 / \mathrm{j}$.arch.20160601.01

[7] Canizaro, V. B. (2007). "Introduction." Architectural Regionalism: Collected Writings on Place, Identity, Modernity, and Tradition. Ed. Canizaro. New York: Princeton Architectural pp. 16-33.

[8] Curtis, W. J. R. (1986). Towards an Authentic Regionalism. Mimar 19: Architecture in Development, edited by Hasan-Uddin Khan. pp 2431. Singapore: Concept Media Ltd.

[9] Daher, R. (2008 a) Amman's Vanishing Legacy of Modernity. Jordan Property, Issue 23, complimentary copy, pp. 10-21

[10] Daher, R. (2008 b) Celebrating and Qualifying Amman: The City of Many Hats. Jordan Property, Issue 14, pp. 32-39

[11] Daher, R. (2008 d) Amman: Disguised Genealogy and Recent Urban Restructuring and Neoliberal Threats. In El-Sheshtawi, W. (ed.) The Evolving Arab City: Tradition, Modernity, and Urban Development. Great Britain: Routledge. pp. 37-68

[12] Dumper, M., Bruce E. Stanley B. E. (2007). Cities of the Middle East and North Africa: A Historical Encyclopedia. ABC-CLIO. p. 35.

[13] Fethi, E., Mahadin, K. (1994). Villa Architecture in Amman: The Current Spectrum of Styles. In the City and its Society, French Centre for the Study of Contemporary Middle East (CERMOC) 6-8.6.

[14] Groat, L., Depres, C. (1991) The significance of Architectural Theory for Environmental Design research. In Zube, E., Moore, G. et.al. Advances in Environment, Behavior, and Design. pp 3-52. New York and London: Plenum Press.

[15] Herring, S. (2009). Regional Modernism:

a reintroduction. In MFS Modern Fiction Studies, Volume 55, Number 1, pp. 1-10

[16] Jarrar, Ola. (2013).Cultural Influences in Jordanian Architectural Practices: Post 1990. University Of Calgary

[17] Jupp, J. Gero. J. (2006).Visual style: Qualitative and context-dependent categorization. Artificial intelligence for engineering design analysis and manufacturing. 20(3):247-266.

[18] Kenneth F. (1983). Towards a Critical Regionalism: Six Points for an Architecture of Resistance. In Foster, Hal ed. The Anti-Aesthetic: Essays on Postmodern Culture. Seattle: Bay Press.
[19] Knight, Terry (1994). Transformations in Design: A Formal Approach to Stylistic Change and Innovation in the Visual Arts. Cambridge: Cambridge University Press

[20] Kulb, D. (1992). Postmodern Sophistications:

Philosophy, Architecture, and Tradition. 1st Ed. University of Chicago Press.

[21] Mahadin, K. (1994) Regionalist Architecture in Jordan: a Critical View. In Open House Internationa, Vol. 3, no. 3, pp. 12-22

[22] Melnik, V. (2019). Urban identity of Amman

A Dialogue between Tradition and Modernity. In Journal of Engineering and Architecture Vol. 7, No. 1, pp. 68-82.

[23] Meyer S. (1953). Style. in Anthropology Today: An Encyclopedic Inventory, ed. A. L. Kroeber (Chicago, pp 287-312.

[25] Mitchell, W. J. (1990). The Logic of Architecture: Design, Computation, and Cognition. Cambridge: MIT Press

[26] Ozkan, S. (2007) Regionalism within Modernism. In Canizaro, V. (ed.). Architectural Regionalism: Collected Writings on Place, Identity, Modernity, and Tradition. pp. 102-109. New York: Princeton Architectural Press. (originally published in 1985).

[27] Pidler, a. D. (2011). Urbanization and Identity:

The Building of Amman In The Twentieth Century. Master's thesis. Miami University, Oxford Ohio

[28] Ricoeur, P (2007). Universal Civilization and National Cultures. Architectural Regionalism: Collected Writings on Place, Identity, Modernity, and Tradition. Canizaro, V. (ed.). pp. 43-53. New York: Princeton Architectural Press.

[29] Schapiro, M. (1953). An Excerpt from Style. White Paper, http://homepages.neiu.edu/ wbsieger/Art202/202Rea d/202Schapiro.pdf, Access date, 10/7/2016

[30] Schmitz, S. (2009). Identity in Architectue? A Construction? In Herrle, P., Schmitz, S. Constructing Identity in Contemporary Architecture: Case Studies from the South (HABITAT - INTERNATIONAL: Schriften der Habitat Unit, Fakultat VI Planen Bauen Umwelt der TU Berlin)

[31] Shalunts G., Haxhimusa Y., Sablatnig R. (2011). Architectural Style Classification of Building Facade Windows. In: Bebis G. et al. (eds) Advances in Visual Computing. ISVC 2011. Lecture Notes in Computer Science, vol 6939. Springer, Berlin, Heidelberg 